Scientific Journal of October 6 University

ISSN (Print): 2314-8640

ISSN (Electronic): 2356-8119

Published by October 6 University (C) All Rights Reserved

Available online at: http:// sjou.journals.ekb.eg

Original Article
Citation: Tarek et al., (2017). Improvement of Productivity Using Tromp Curve Measurement for Cement Separator Processing Technology. Sci.J. of Oct. 6 Univ. 3(2), 35- 44.

Copyright: (C) 2017 Tarek et al., This is an open-access article distributed under the terms of the Creative Commons Attribution License, which permits unrestricted use, distribution, and reproduction in any medium, provided the original author and source are credited.

\title{
Improvement of Productivity Using Tromp Curve Measurement for Cement Separator Processing Technology
}

\author{
*T. k. Belhaj, M. G. Higazy, A. M. Gaafer and B. A. K. ELMogy \\ Mechanical Engineering Department, Faculty of Engineering Shoubra, Benha University; \\ Received: 10-04-2016 \\ Revised: 18-04-2016 \\ / Accepted: 20-6-2016

\begin{abstract}
This paper is carried out to examine the potential to improve productivity by optimizing the grinding circuit (e.g. separator performance), measuring cement fineness by different fineness indicating parameters, to obtain the separator efficiency under different separator speeds This will allow to determine the effect of adjusting parameters on the specific surface area and particle size distribution of the final product and This is used to determine the effect of adjusting parameters on the specific surface area and particle size distribution of the final product using Markov chain model. The evaluation of the separator performance test shows that separator efficiency is good, bypass is low and sharpness of separation is sufficient.
\end{abstract}

Keywords: Tromp Curve, Cement Separator, Portland, Improvement of Productivity

\section{Introduction}

In general grinding process is ideal when the particle feed is charged from grinding mill with minimum time required to obtain its finest shape. Therefore the required force for grinding would be applied only for oversize particles. This is attempt will reduce all the feed to finished but will results in highly costly process.

To carry out the above process from grinding circuit, sizing device such as an air separator is used and the oversize constitutes the circulating load to the mill. A Simplified Schematic of a Dry Cement Manufacturing Process is shown in Fig. 1. Thus, a particle with certain maximum size are stopped from leaving the mill, and those below the desired size are not recirculated once again through the grinding circuit.

The separation process itself has an important effect on grinding performance in the mill, and thus it is important to determine the characteristic performance of the process. The appropriate operative process is mainly affected by:

1-The separator operating parameters and technical specification e.g. number and position of spin rotor blades, distributor plate speed, , wear on fan and spin blades, air in-leaks... etc.

2-The condition of separator feed, e.g. particle size distribution, feed rate, density, moisture content etc.

3-Feed air condition to the separator, e.g. temperature, density, viscosity, moisture content... etc.

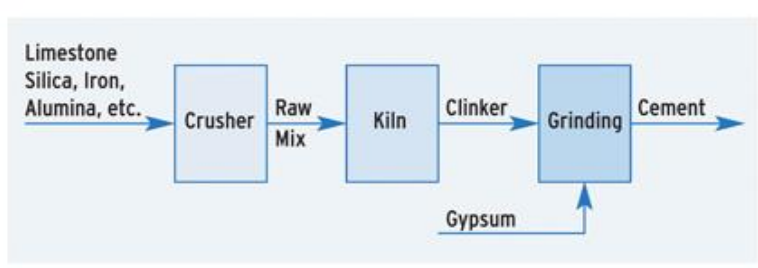

Fig. (1): A Simplified Schematic of a Dry Cement Manufacturing Process.[2]

\section{Field Experiments}

The separator material streams were sampled for three different separator speeds: nominal, increased, and decreased, at a constant air flow rate. To characterize the separator performance at the given separator rotor speeds, the three separator material streams (feed, rejects, and fines) had to be sampled and analyzed. The material sampling locations, where at $0,1,2$, and 3 which correspond to the fresh feed (0), separator feed (1), rejects flow (2), and final product (3). [Cement engineering book]

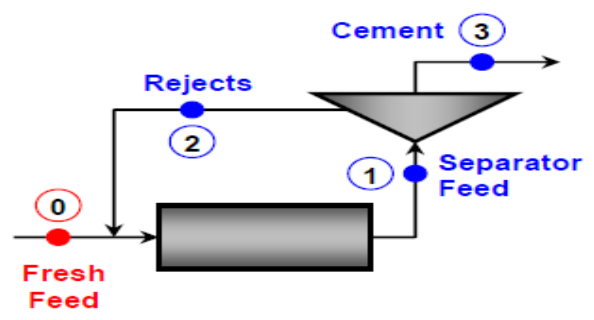


Fig. (2): Sampling Points [Mejeoumov GG (2007)]

Field experiments were carried out to measure the fineness of cement through different tests; Sieve Analysis of the fresh feed mix and air permeability test (Blaine test) of the final product. The Particle size distributions (PSD) of the three separator streams were obtained via Laser light scattering technique. All experiments were done at three different separator speeds. In addition, data regarding the improvements in the closed circuit after installation of high efficiency separators (HES) was also collected.[ Alsahhar A.Cement, ASTM C204-11(2014)]

a)

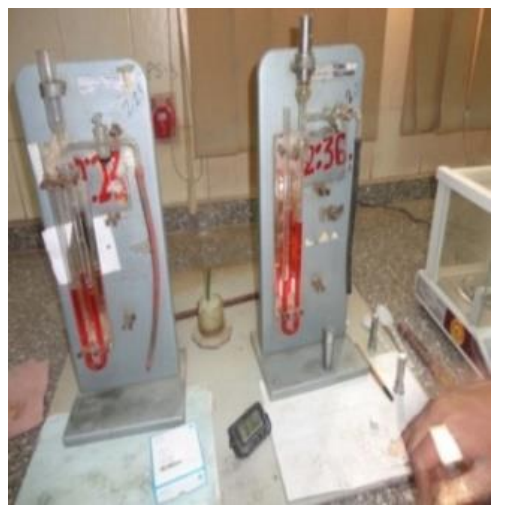

b)

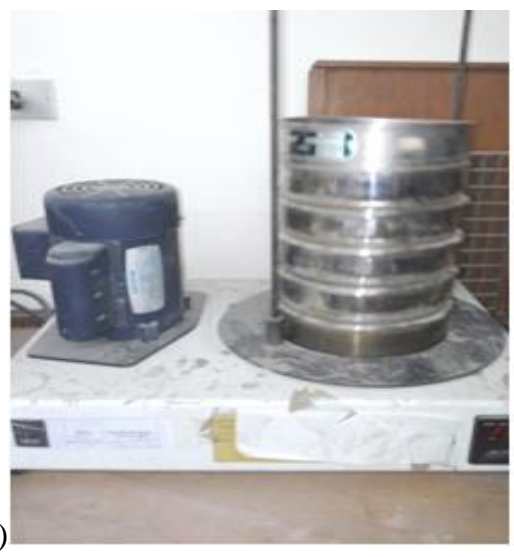

(c)

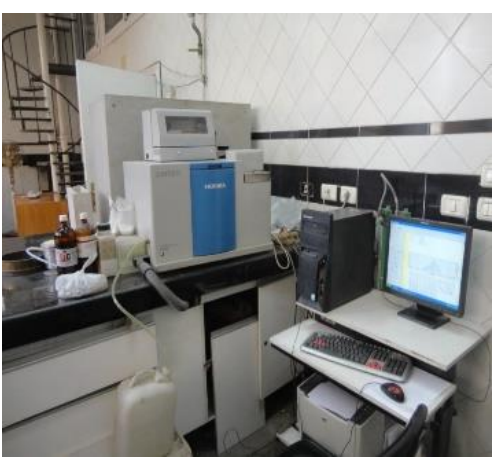

Fig. (3): (a) Blaine Testing, (b) Sieve Analysis, (c) Horiba Laser

The material is then evenly distributed by the centrifugal force into the annular gap between the rotor and the guide vanes and forms a thin cylindrical curtain in the classifying zone.[6]

Here, the individual particles are subjected to four forces:

1. The air carries the material around at about the rotational speed of the rotor.

2. The radial air drag force is trying to pull the material inside the rotor.

3 . The centrifugal force is trying to push the material towards the guide vanes.

4. The gravity force is pulling the material down.

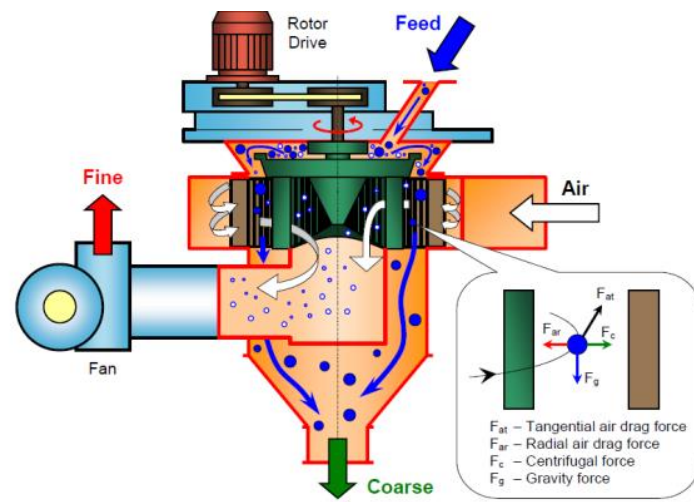

Fig. (4): The Four Separating Forces Affecting the Particle in the Separation Zone.[ Mejeoumov GG

(2007)]

\section{Properties of the Closed Grinding Circuit}

One of the characteristics of the closed milling system is the particle size distribution of the material in each stream of the circuit. The PSD (particle size distribution) of the material entering the mill is comprised of the size distributions of the fresh feed, $\left(B_{0}\right)$, and the separator rejects, $\left(B_{2}\right)$.To evaluates the recirculation of the coarse particles in the circuit, correlated parameter is calculated: Circulating load. The circulation load is the average number of times that the material circulates through the circuit before becoming the product. A harder clinker will yield a higher circulation load. It is defined by the ratio of the mill's throughput, $B_{1}$, to the product flow rate, $B_{3}$. The circulating factor is the quantity of the separator rejects, $B_{2}$, compared to the quantity of the final product, $B_{3}$. [8 ]

$$
\begin{aligned}
& C . F=\frac{B_{1}}{B_{3}}=\frac{B_{0}+B_{2}}{B_{0}} \\
& C . L=\frac{B_{2}}{B_{3}}=\frac{B_{2}}{B_{0}}
\end{aligned}
$$

Where:

- C. $L-$ Circulation load of the closed milling circuit

- C.F-Circulation factor of the closed milling circuit 
It also should be noted that the circulation load can be calculated for each individual fraction determined by the laser particle size analyzer using separator material PSD data, expressed in the form of the individual retained functions, $f(x)$.

$$
C . L_{i}=\frac{B_{1}}{B_{3}}=\frac{f_{3 i}-f_{2 i}}{f_{1 i}-f_{2 i}}
$$

\section{C. $L_{i}$ - Circulation load of the $i$-th fraction.}

\section{Measuring of the Efficiency of Separation}

The three material streams surrounding the separator are:

1. Feed 2. Reject 3. Fine material [7]

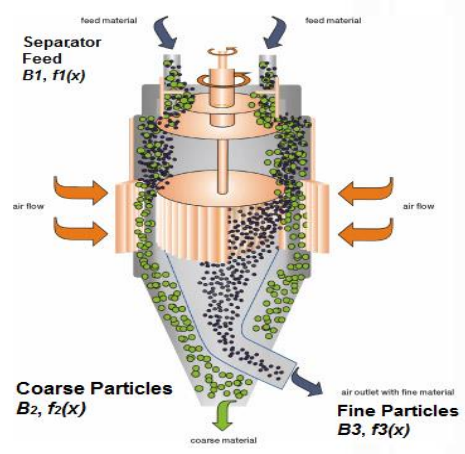

Fig. (5): Material Streams Surrounding the Separator. [

Cement and Mining Processing (CMP)AG;2010]

The classifier splits up the feed material into two separate streams: rejects and fines. All three material streams are characterized by their individual mass flow rate, $\mathrm{B}$, and particle size distribution, $f(x)$. the typical PSD data describing the three material streams surrounding the HES are shown in Fig. (6).

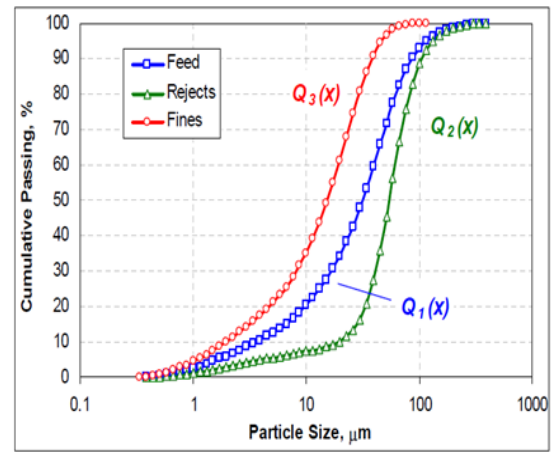

(a)

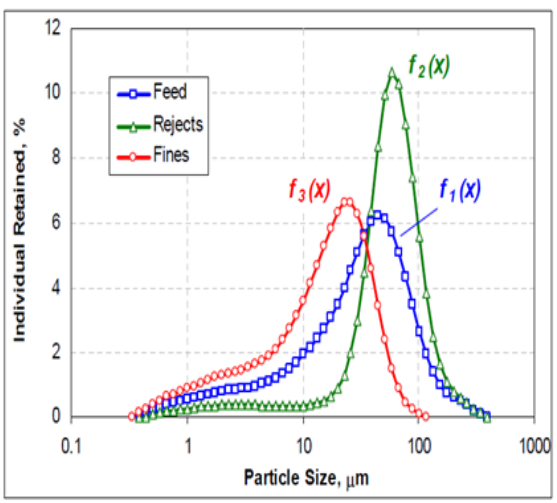

(b)

Fig. (6): PSD of the Material Streams Surrounding Separator ( $\mathrm{a}$ - Cumulative Passing PSD; $\mathrm{b}$ - Individual Retained PSD).[9,8]

In order to evaluate efficiency of the separation process, the Tromp curve of the separator is calculated and widely used throughout the cement industry. The Tromp curve shows percent of the material in each individual size fraction that is recovered into the coarse stream. The opposite of the Tromp curve is the grade efficiency curve (GEC), which defines percent of the material in each fraction recovered into the fine stream. [Mizonov et.al (1997), Bhattyet.al (2004)]

\section{The Tromp Curve [Bhattyet.al (2004)]}

The Tromp curve can be derived from the basic principle of mass balance: The amount of material supplied to the separator is equal to the amount of material leaving it. In a steady-state operation, the mass flow of the fresh feed is equal to the sum of mass flows of fine and coarse streams.

$$
B_{1}=B_{2}+B_{3}
$$

Where:

$B_{1}, B_{2}, B_{3}$ Mass flow of the feed and coarse and fine streams, mass per time unit.

Where:

$$
B_{1} \cdot f_{1 i}=B_{2} \cdot f_{2 i}+B_{3} \cdot f_{3 i}
$$

$f_{1 i}, f_{2 i}, f_{3 i}$ : Portion of the material in the $\mathrm{i}$-th fraction of the feed and coarse and fine streams.

The Tromp value for the $\boldsymbol{i}-\boldsymbol{t} \boldsymbol{h}$ fraction is defined by the probability of the feed particles to occur in the coarse stream and equals the ratio of the coarse fraction mass to the feed fraction mass.

Tromp curve is defined as:

$$
\operatorname{Tromp} p_{i}=\frac{B_{2} \cdot f_{2 i}}{B_{1} \cdot f_{1 i}}(6)
$$

$$
\text { Tromp Curve }=\frac{f_{2 i}}{f_{1 i}} \cdot \frac{f_{1 i}-f_{3 i}}{f_{2 i}-f_{3 i}} \text { (7) }
$$

Grade Efficiency Curve is then defined by:

$$
G E C=\frac{f_{3 i}}{f_{1 i}} \cdot \frac{f_{1 i}-f_{2 i}}{f_{3 i}-f_{2 i}}(8)
$$




\section{Particle Size Distribution with its Rosin-Rammler representation and Tromp Curves}

In order determine the performances of a separator; generally the Tromp curve also called separation curve or selectivity curve are used. From Tromp curves various parameters are generated allowing comparison of one separator with other generations of separators.

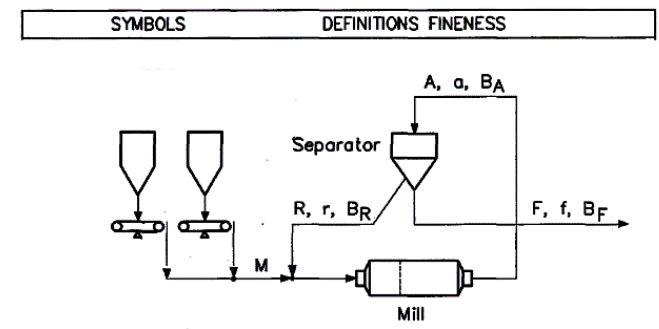

Fig. (7): Theory Tromp Curve.

Table (1): Symbols Used For Mass Balances.

[ Holderbank management and consulting(1993)]

\begin{tabular}{|c|c|c|c|}
\hline Description & $\begin{array}{c}\text { Mass } \\
\text { flow } \\
{[\mathbf{t} / \mathbf{h}]}\end{array}$ & $\begin{array}{c}\text { Fineness } \\
\text { Passing } \\
{[\%]}\end{array}$ & $\begin{array}{c}\text { Spec. Surface } \\
\text { Blaine }\left[\mathbf{m}^{2} /\right. \\
\mathbf{k g}]\end{array}$ \\
\hline Mill feed & $\mathrm{M}$ & - & - \\
\hline $\begin{array}{c}\text { Separator feed } \\
\text { mill discharge }\end{array}$ & $\mathrm{A}$ & $\mathrm{a}$ & $B_{A}$ \\
\hline $\begin{array}{c}\text { Fine fraction } \\
\text { (product) }\end{array}$ & $\mathrm{F}$ & $\mathrm{f}$ & $B_{F}$ \\
\hline $\begin{array}{c}\text { Coarse } \\
\text { fraction } \\
\text { (Tailing) }\end{array}$ & $\mathrm{R}$ & $\mathrm{r}$ & $B_{R}$ \\
\hline
\end{tabular}

In a steady state, let's pose the following two equations:

$$
\begin{gathered}
A=R+F \\
\mathrm{~A}^{*} \mathrm{a}=\mathrm{R}^{*} \mathrm{r}+\mathrm{F}^{*} \mathrm{r}
\end{gathered}
$$

a, r, f : passing at a certain sieve of the separator feed and in rejects and fines $\%$

The percentage of fines leaving the separator in relation to the quantity fed to the separator is defined $(V a)$ :

$V_{a}=\frac{F}{A} * 100=\frac{a-r}{f-r} * 100$

From $V a$, we define $V r$ :

$$
V_{r}=1-V_{a}
$$

\section{Circulation Factor Calculation}

The circulation factor can be calculated in various ways and is also called circulating load, the circulation factor is the ratio feed/fines and is defined by:

$$
C . F=\frac{A}{F}=\frac{f-r}{a-r}
$$

It is noticed that it is the reverse of $(V a)$, The circulating load will be the ratio tails/fines (often expressed in \%) is defined by:

$$
C . L=\frac{f-r}{a-r} * 100=(C . F+1) * 100
$$

Theoretically, the circulation factor must be equal for all sieves but it is not the case in reality. A well accepted method is to calculate the average.

\section{Separator Efficiency}

The separation efficiency is the proportion of passing at a certain sieve which passes from the feed to the fines in \%. Its equation is:

$\eta=\frac{a-r}{f-r} * \frac{f}{a} * 100=V_{a} * \frac{f}{a} * 100 \%$

The separation's efficiency doesn't give any idea of what proportion of fines particles go back to the rejects. It is why the Tromp curve has been developed.

\section{Measuring the Efficiency Tromp Curve [Holderbank management and consulting (1993), Benzer et.al (2001)]}

The Tromp curve is an effective tool to evaluate separator performance. The Tromp curve is a chart showing the probability of a given size of particle in the separator feed that will go to the rejects. This probability is also called "degree of selectivity". This probability is calculated on each size fraction of the sample. A size fraction is for example the passing in \% between $4 \mu$ and $8 \mu$ of the feed, the general formula to express the Tromp curve for each fraction size is:

$$
\begin{aligned}
T=\frac{V_{r} * \Delta_{r}}{V_{r} * \Delta_{r}+V_{a} \Delta_{f}} & (16) \\
& \Delta_{a}, \quad \Delta_{r}, \Delta_{f} \text { : fraction of }(a, r, f) \text { for a }
\end{aligned}
$$
defined interval in \%

\section{Tromp curve parameters}

The Tromp curve has several features important for evaluating the separation process. The Tromp curve assigns them numerical values: (Cut size value, Sharpness of separation, Bypass value) [FLSmidth(2010)] 


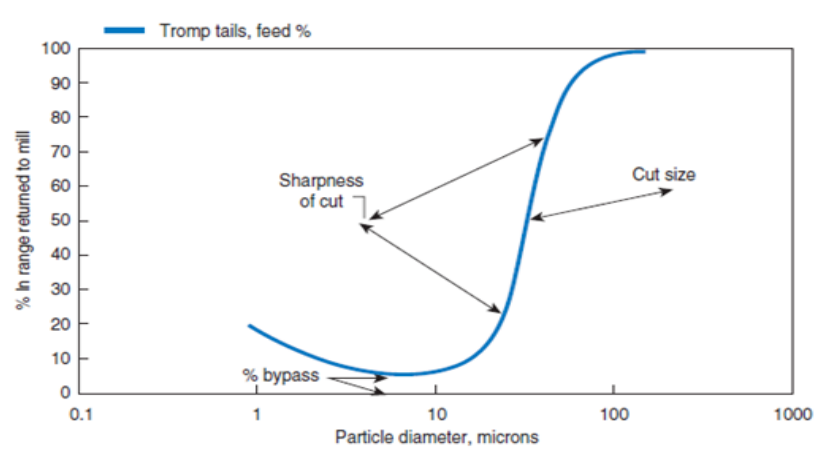

Fig. 9: Tromp Curve Parameters [Benzer et.al (2001)]

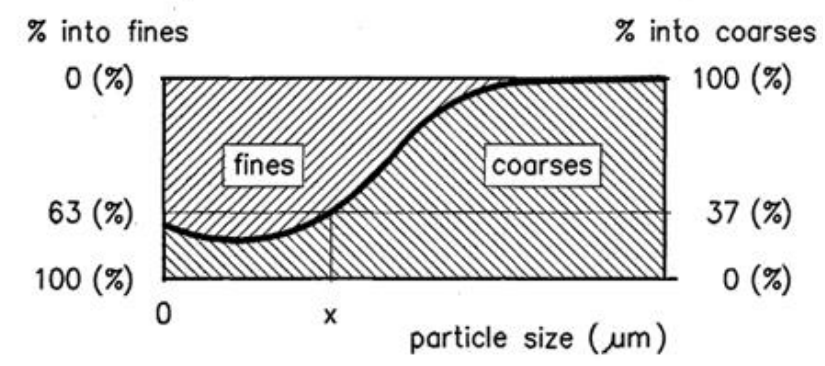

Fig. 10: Cut Size [Benzer et.al (2001)]

1- The cut size d50 corresponds to $50 \%$ of the feed passing to the coarse stream as see in Fig. (10). It is therefore that size which has equal probability of passing to either coarse or fine streams.

\section{2- sharpness of separation}

The sharpness of separation of is defined as follows:

$$
S h=\frac{d_{75}}{d_{25}}(17)
$$

Where: $d_{25}$ And $d_{75}$ - Particle sizes with Tromp values of $25 \%$ and $75 \%$. (An ideal separator has a $S h$ of 1). [14] (Fig. 11)

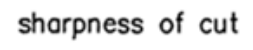

shorpness of cut

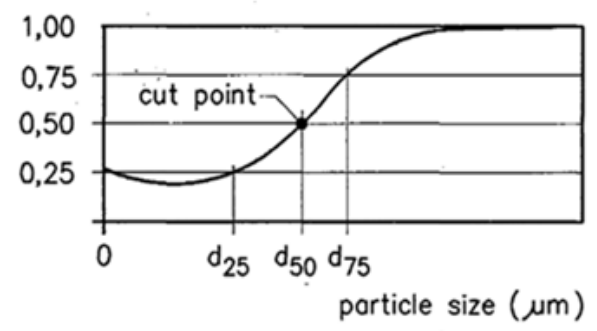

Fig. 11: The Sharpness of Separation

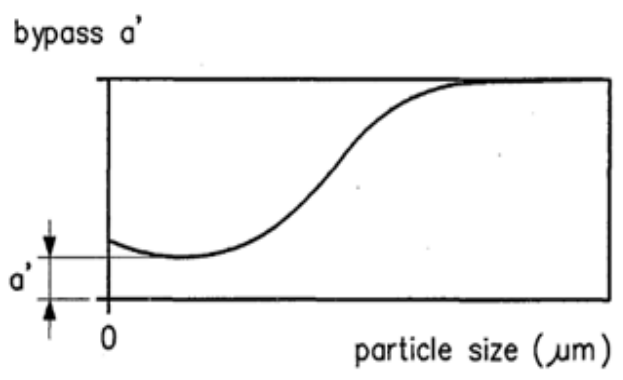

Fig. 12: The bypass value

\section{3- By-pass}

The bypass value defines the portion of the material that bypasses the classifying action. It is the part of the feed that reports to the coarse stream independently of its particle size due to agglomeration of the fine particles. Therefore, it is immediately returned to the finish mill with the rejected material. [Holderbank management and consulting (1993), Benzer et.al (2001]

\section{D limit (Limit dimension):}

On the left of this point, the curve rises again. It means that there is no more selective separation below $\mathrm{D}$ limit. The high-raised "tail" to the left of the minimum of the Tromp curve shown in (Fig. 13) is another consequence of agglomeration of the fine particles and called the "fish-hook" effect .Due to the frictional nature of grinding in the second compartment of the mill, the electrostatic charges are imposed upon the particles leaving the mill. The smaller (lighter) particles are more susceptible to the electrostatic forces and tend to coat larger particles and/or stick together, forming agglomerates.

\section{Imperfection Factor [Bhattyet.al (2004)]}

The imperfection factor gives an excellent idea of the separator behavior. It is also good to compare between separators. It is given by the following formula:

$$
I=\frac{d_{75}-d_{25}}{2 * d_{50}} \text { (18) }
$$

Where: $\boldsymbol{d}_{\mathbf{7 5}}, \boldsymbol{d}_{\mathbf{5 0}}$ is and $\boldsymbol{d}_{\mathbf{2 5}}$ are the dimensions in $\mu \mathrm{m}$ at $75 \%, 50 \%$ and $25 \%$ in the $\mathrm{y}$-axis of the curve. It should be as small as possible. Usual Fig.s and grades:

\begin{tabular}{|l|l|}
\hline \multicolumn{1}{|c|}{ I $<0,2$} & $0,4<\mathrm{I}<0,6$ \\
Excellent separator & Poor separator \\
$0,2<\mathrm{I}<0,3$ & $0,6<\mathrm{I}<0,7$ \\
Good separator & Bad separator \\
$0,3<\mathrm{I}<0,4$ & $\mathrm{I}>0,7$ \\
Normal separator & Execrable separator \\
\hline
\end{tabular}

The agglomerates are treated by the separator as particles of larger size and have a higher probability of passing into the coarse stream. Grinding aids help to reduce agglomeration by relieving some of the electrostatic charges imposed upon the particles and thus improve recovery of the fine particles into the product stream. The efficiency of the classification process can be assessed by comparing the real life 
separator (Fig.13) to that of an ideal one. The ideal separator would have a Tromp curve completely vertical at the cut size, i.e., characterized by the sharpness of separation $S h=1$ and, bypass $=0$.

(a)

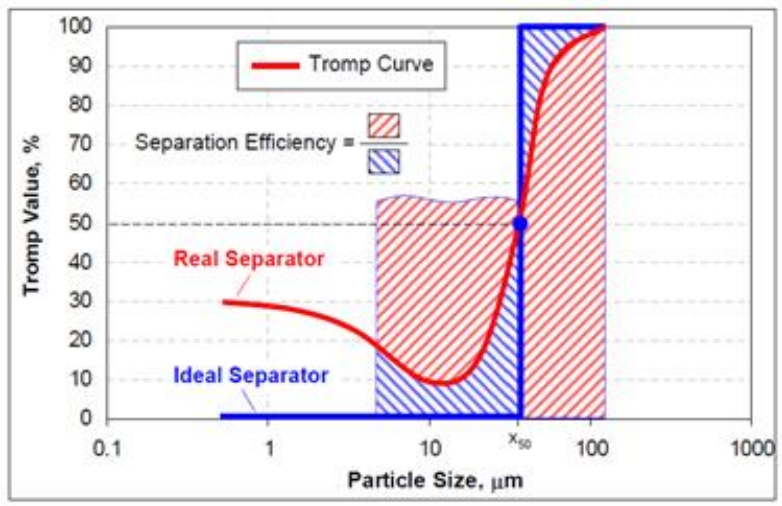

(b)

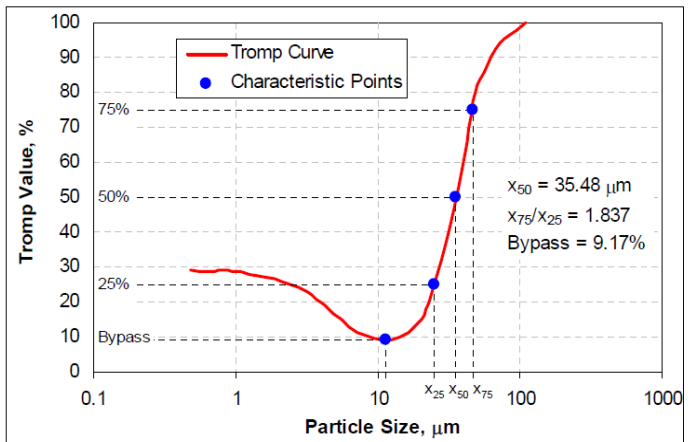

Fig. 13: (a) Tromp Curve of the High Efficiency Separator, (b) Efficiency of the Separator Using Ideal Tromp Curve.

All particles larger than the cut size would be sent to rejects $($ Tromp $=100 \%$ ), whereas all particles smaller than the cut size would be recovered into the final product (Tromp $=0 \%$ ) - See Fig. (14) the ratio of the areas under the Tromp curves of the real and ideal separators defines the separation efficiency.

The cut size is commonly defined as the particle size at which there is equal probability of the feed passing to either the coarse or fine streams. The ideal cut size is between 25 and 30 microns. The sharpness of cut is measured by the ratio of $\left(d_{75} / d_{25}\right)$. The nearer the ratio is to 1.0 , the sharper the separation.

An additional but less important feature is the 'fish hook effect' commonly seen in classification curves. It is associated with the finer particles and shows the degree of return of fine particles to the coarse stream. The following factors may cause this effect:

- Larger particles are coated with finer particles.

- Incomplete feed dispersion.

- $\quad$ Fines are entrained in the rejects.
- Aggregations of fine particles that pass into the coarse stream.

It needs to be remembered that the Tromp curve is an indication of how the separator is working and not an indication of the entire mill system

\section{Tromp Curve Reduced}

On the left of the D limit, the finest particles are following the flow and are split between the rejects and the fines in a total incertitude. There is no more separation in this zone. In order to remove the effect of that zone, the Tromp curve is reduced by the following equation Fig. (15)

$$
T_{r}=\frac{T-B_{p}}{1-B_{p}}
$$

\section{$\operatorname{Tr}=$ Tromp reduced, $B p=$ By-pass $[8]$}

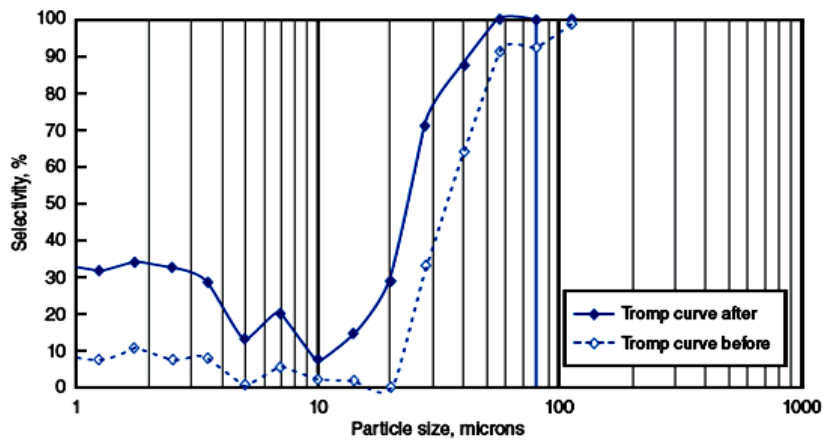

Fig. (15): Tromp Curve Reduced

13. The Markov chain theory was introduced to describe the processes of grinding, classification, and particle transport in a closed finish mill circuit. It was utilized to allow calculation of all parameters of continuous grinding process in a mill.

Using the identified Markov chain model, the ideal grade efficiency curve was simulated and analyzed. Simulation showed that PSD followed the shape of ideal separation, the specific surface area increased and the calculated $45-\mu \mathrm{m}$ sieve passing value was $100 \%$ indicating that all the final product was finer than the cut size.

\section{Results and Discussion}

Table (2): Comparison of the (Production Rate, Energy Consumption and Blaine Value) Before and After Installation of a High Efficiency Separator

\begin{tabular}{|c|c|c|c|c|}
\hline $\begin{array}{c}\text { Cement } \\
\text { Mill }\end{array}$ & System & $\begin{array}{c}\text { Production } \\
\text { rate } \\
{[\text { ton } / \boldsymbol{h}]}\end{array}$ & $\begin{array}{c}\text { Energy } \\
\text { consumption } \\
{[\boldsymbol{k} \text {. W. } \boldsymbol{h} / \text { ton }]}\end{array}$ & $\begin{array}{c}\text { Blaine } \\
\text { value } \\
{\left[\mathbf{m}^{\mathbf{2}}\right.} \\
\mathbf{k g}]\end{array}$ \\
\hline \multirow{5}{*}{ Ball Mill } & Open Circuit & $90-100$ & 60 & $310-320$ \\
\cline { 2 - 5 } & $\begin{array}{c}\text { Closed } \\
\text { Circuit } \\
\text { With(high } \\
\text { Efficiency } \\
\end{array}$ & $110-130$ & $42-48$ & $350-380$ \\
\hline Separator) & & & \\
\hline
\end{tabular}


The results of the field experiments showed that all the fineness indicating and Tromp curve parameters were consistent with the testing conditions, also the separator showed normal separation at all speeds. The data collected showed that installation of high efficiency separators improved the production rate and quality and decreased the energy consumption. Results of the field experiment were then utilized to identify the model's parameters.

Table (3): Lab Blaine Results at different Separator Speeds

\begin{tabular}{|c|c|}
\hline Separator speed & Lab Blaine $\left[\boldsymbol{m}^{\mathbf{2}} / \boldsymbol{k g}\right]$ \\
\hline High speed & 396 \\
\hline Normal speed & 381 \\
\hline Low speed & 359 \\
\hline
\end{tabular}

Results of the lab Blaine surface values showed the highest values for the high separator speed and the lowest values for the low separator speed. This was consistent with the testing conditions. The high separator speed rejects coarser particles producing a finer product. The finer the product the higher the surface area values (high Blaine results).

15. Efficiency of Separation: (A sampling campaign gives the following results)

\begin{tabular}{|c|c|c|}
\hline Size & Efficiency \% & Tromp \% \\
\hline 1 & 74.7 & 23.38 \\
\hline 2 & 75.08 & 24.99 \\
\hline 4 & 74.43 & 22.73 \\
\hline 8 & 79.22 & 13.37 \\
\hline 16 & 81.05 & 9.45 \\
\hline 24 & 83.55 & 13.14 \\
\hline 32 & 75.67 & 35.08 \\
\hline 45 & 68.46 & 63.83 \\
\hline 64 & 57.7 & 84.71 \\
\hline 90 & 52.63 & 95.29 \\
\hline 120 & 50.73 & 98.52 \\
\hline 150 & 49.63 & 100 \\
\hline 175 & 49.3 & 100 \\
\hline 200 & 49.07 & 100 \\
\hline
\end{tabular}

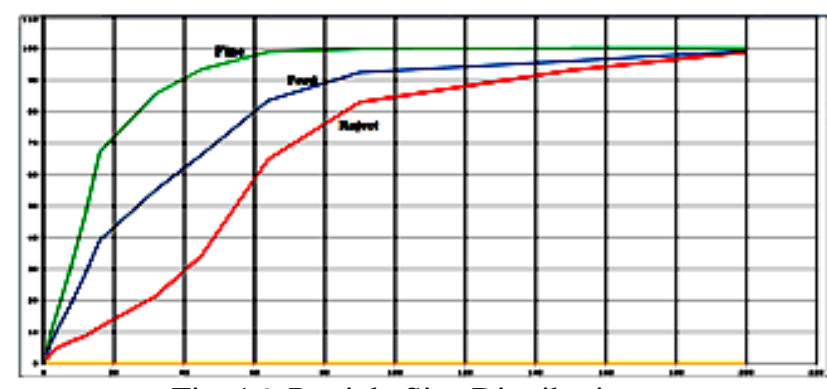

Fig. 16: Particle Size Distribution.

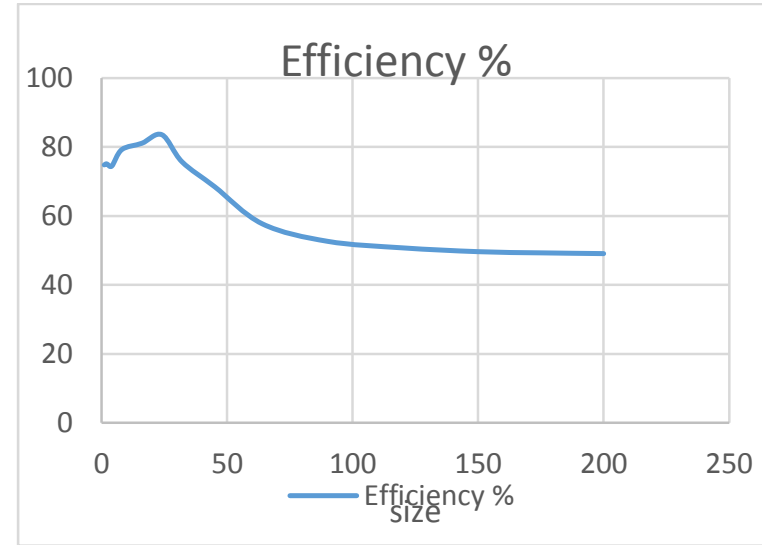

Fig. 17 : Efficiency of Separation

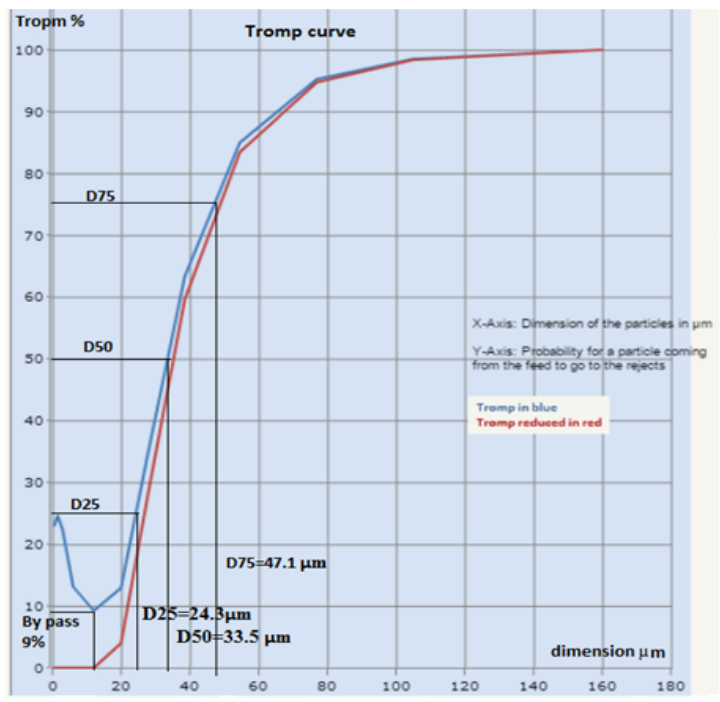

Fig. 18: Tromp Curve

\section{- Separator evaluation}

Cut size $\left(d_{50} \%\right) \quad 33.5 \mu \mathrm{m}$ this is a good estimation.

$\mathrm{D}$ limit: $12 \mu \mathrm{m}$ this is a rough estimation. 
- Imperfection :With the formula: $I=$ $\frac{d_{75 \%}-d_{25 \%}}{2 * d_{50 \%}} \quad I=\frac{47.1-24.3}{2 * 33.5}=0.34$

Sharpness factor $(\boldsymbol{S h})=d_{75} / d_{25}=47.1 / 24.3=1.93$

- The sharpness of separation was the highest at the normal separator speed $(S h=1.93)$, the higher sharpness of separation value corresponds to a narrower size range of particles. However, all speeds showed sharpness ranging between (1.821.93) which was close to the expected 2.0.

- This separator has a Normal imperfection indicating a normal separator behavior, the $\mathrm{D}$ limit and the By-pass are satisfactory.

- Although all separator speeds showed normal behavior, but the bypass values were good (less than $10 \%)$ at all separator speeds.

Table (4) :Tromp Curve Results

\begin{tabular}{|c|c|c|c|c|c|c|c|c|}
\hline $\begin{array}{c}\text { Tromp } \\
\text { curve } \\
\text { parameters }\end{array}$ & $\begin{array}{c}\mathbf{C . L} \\
{[\boldsymbol{\%}]}\end{array}$ & $\begin{array}{c}\boldsymbol{d}_{\mathbf{2 5}} \\
{[\boldsymbol{\mu \mathrm { m } ]}}\end{array}$ & $\begin{array}{c}\boldsymbol{d}_{\mathbf{5 0}} \\
{[\boldsymbol{\mu \mathrm { m } ]}}\end{array}$ & $\begin{array}{c}\boldsymbol{d}_{\mathbf{7 5}} \\
{[\boldsymbol{\mu \mathrm { m } ]}}\end{array}$ & $\mathbf{S h}$ & $\mathbf{I}$ & $\begin{array}{c}\text { By } \\
\text { Pass } \\
{[\mathbf{\%}]}\end{array}$ & $\begin{array}{c}\mathbf{D} \\
\mathbf{L i m i t} \\
{[\boldsymbol{\mu m}]}\end{array}$ \\
\hline $\begin{array}{c}\text { High } \\
\text { separator } \\
\text { speed }\end{array}$ & 74 & 24.5 & 33.4 & 46.6 & 1.90 & 0.33 & 5.8 & 12 \\
\hline $\begin{array}{c}\text { Normal } \\
\text { separator } \\
\text { speed }\end{array}$ & 103 & 24.3 & 33.5 & 47.1 & 1.93 & 0.34 & 9.5 & 12 \\
\hline $\begin{array}{c}\text { Low } \\
\text { separator } \\
\text { speed }\end{array}$ & 86 & 28.0 & 36.3 & 51.1 & 1.82 & 0.32 & 7.2 & 12 \\
\hline
\end{tabular}

- The separator behavior didn't change with the change of the speed, in the low separator speed, Imperfection $(\mathbf{I})=0.32$, for the normal speed $(\mathbf{I})=0.34$ and for the high speed $(\mathbf{I})=0.33$. All separator speeds showed Normal Separation.

- The lower separator rotor speed rejects less coarse particles; it yields a lower fineness of the final product. On the other hand, higher separator rotor speed rejects more course particles and leads to a higher fineness of the final product, and that was consistent with the results where the curve of the high speed was shifted to the left towards the smaller particle size and (lower $\left.x_{50}\right)$. Although the range between different sizes was narrow but still, the variable separator speed test revealed a definite relationship between the separator rotor speed and the fineness characteristics of the final product.

- The smaller the cut size value, the finer the final product, and that was consistent with the results where:

- The high-speed separator showed the smallest cut size value $x_{50}=33.4 \mu \mathrm{m}$, while the normal speed $x_{50}=33.5 \mu \mathrm{m}$ and the low speed $x_{50}=36.3 \mu \mathrm{m}$.
- Although all separator speeds showed normal behavior, but the bypass values were good (less than $10 \%)$ at all separator speeds.

\section{Numerical Simulation and Analysis [12]}

The Markov chain model was constructed and the analysis of the finish mill grinding circuit was performed using the MATLAB software.

\section{Model Identification}

For identification of the parameters of the Markov chain model. The data obtained from the nominal regime "Normal Speed - Normal Air" observed during the experiment was used.The input variables of the model were:

- $Q_{1}(\mathrm{x}), Q_{2}(\mathrm{x}), Q_{3}(\mathrm{x})$, and $Q_{0}(\mathrm{x})-$ Particle size distributions in the cumulative percent passing form describing the separator streams and fresh feed mixture , $\left(B_{0}\right)$ Rate of the fresh feed to the entire circuit.[12]

The measured and calculated particle size distributions of the three separator flows along with the GEC are shown in (Fig.20). In two text columns, the Fig. also presents the identified model parameters. The specific surface area and $45-\mu \mathrm{m}$ sieve percent passing values determined using the measured PSD data of the final product are shown in red color below the modelcalculated parameters. The model-defined specific surface area of $335.75 \mathrm{~m} 2 / \mathrm{kg}$ and $45-\mu \mathrm{m}$ sieve passing of $80.50 \%$ were used as the reference values in further regime simulations.

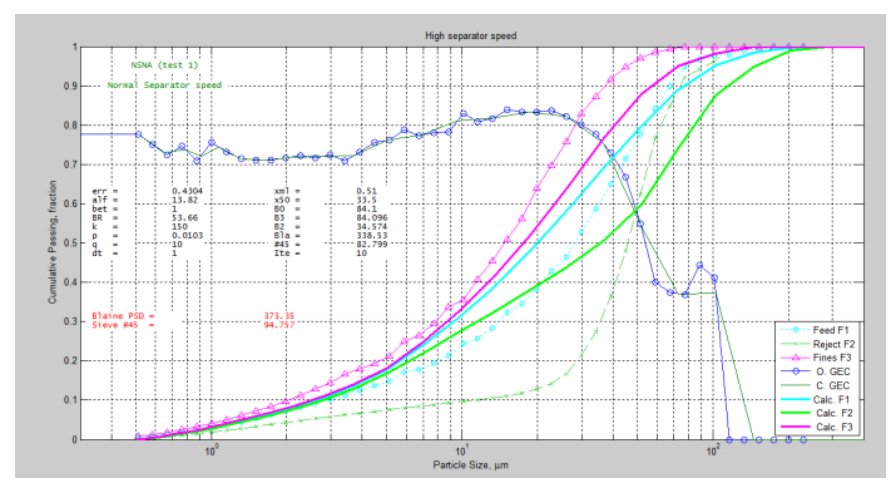

Fig. (20): Simulation of the High Speed Regime

Table (5): Model-Calculated Specific Surface Area vs. Measured Values.

\begin{tabular}{|c|c|c|c|}
\hline $\begin{array}{c}\text { Testing } \\
\text { Regime }\end{array}$ & \multicolumn{3}{|c|}{ Specific Surface Area, $\mathrm{m}^{2} / \mathrm{kg}$} \\
\hline $\begin{array}{c}\text { Separator } \\
\text { Speed }\end{array}$ & $\begin{array}{c}\text { ASTM } \\
\text { C 204 }\end{array}$ & $\begin{array}{c}\text { PSD } \\
\text { Measured }\end{array}$ & $\begin{array}{c}\text { Model } \\
\text { Calculated }\end{array}$ \\
\hline High & 396 & 373.35 & 338.53 \\
\hline Normal & 381 & 360.21 & 335.75 \\
\hline Low & 359 & 346.83 & 332.10 \\
\hline
\end{tabular}


The performance characteristics of cement depend not only on the specific surface area of the material, but also on the proportion of the fine and coarse particles, i.e., the shape of the PSD of cement. Therefore, the model calculated and compared the shape of the PSD of the fines at all the tested regimes: high, normal, and low separator speeds as shown in (Fig. 20).

The model calculated PSD curves at the three tested speeds showed a narrow range. The model calculated PSD of the high speed was shifted to the left toward the smaller particle sizes

\section{Ideal Grade Efficiency Curve}

The most desired property of any separator is to have an efficiency of $100 \%$. This means all particles smaller than the cut size of the separator become final product (none of the coarse particles become the final product) and all particles larger than the cut size become rejects (none of the fine particles escapes to the rejects stream). The grade efficiency curve values of the ideal separator are equal to 1 for all fractions less than $x_{50}$ and 0 for fractions larger than $x_{50}$.

The ideal grade efficiency curve can be simulated using the Markov chain model. The particle size distributions for the Normal Speed operating regime would look like the following if the separator was ideal, almost the entire PSD of the final product, $Q_{3}(x)$, would lie below the cut size of the separator, $x_{50}=33.5$ $\mu \mathrm{m}$, whereas the PSD of the rejected material, $Q_{2}(x)$, would be situated above the cut size. Since all the particles of the final product would be finer than 33.5 $\mu \mathrm{m}$, the $45-\mu \mathrm{m}$ sieve passing value would be $100 \%$ and the specific surface area of the product would increase from $335.75 \mathrm{~m}^{2} / \mathrm{kg}$ of the real classification conditions to $400.06 \mathrm{~m}^{2} / \mathrm{kg}$ of the ideal ones. (Fig.21)

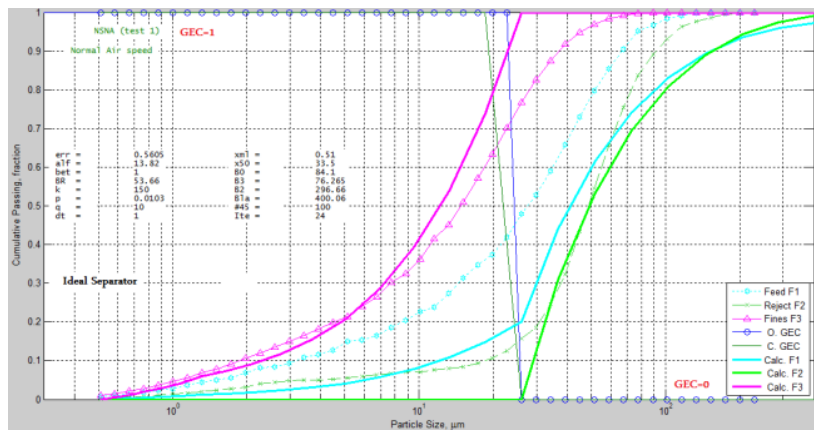

Fig. (21): Simulation of the Ideal Classification.

The increase of the product's fineness level was anticipated due to the following characteristic features of the ideal GEC (or ideal Tromp curve): (Zero By pass, Lack of the "fish-hook" effect, Unit sharpness of separation)

\section{The Effect of Fresh Feed Rate Adjustment on the Grinding Circuit}

Fresh feed rate is one of the parameters that can be adjusted during operation, it is directly related to the production rate, and is an input parameter of the Markov chain model .Therefore; the response to the fresh feed adjustments was simulated using the Markov chain model. Several fresh feed input values were used to calculate the finish mill circuit while all other parameters of the model were kept constant, as shown in (Fig.22).

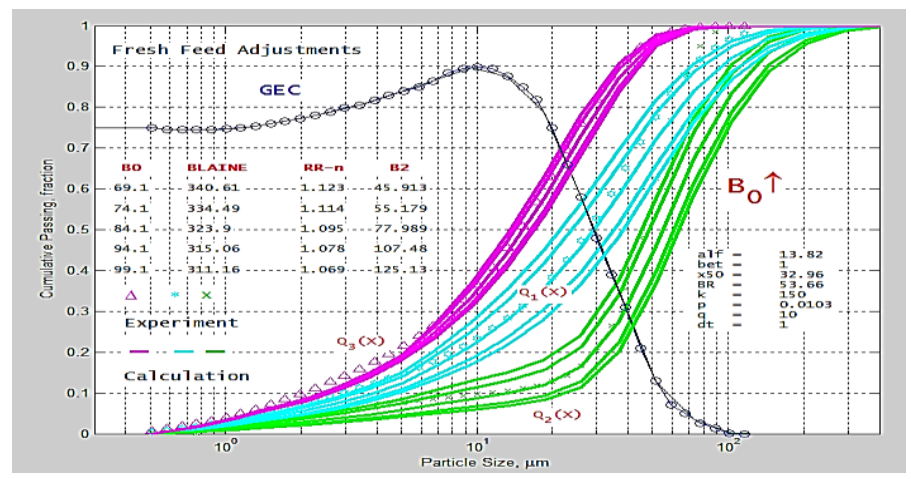

Fig. (22): Model Response to the Fresh Feed Adjustments.

When the fresh feed rate was increased, the specific surface area of the product decreased and the particle size distributions were shifted to the right toward the larger particle sizes. In addition, the PSD became wider which resulted in decreasing in the Rosin-Rammler shape factor, $n$ values.

The response of the circuit to the change in the fresh feed rate was in agreement with the nature of the classification process. When the fresh feed rate increases the material per unit volume of air in the classification zone increases, this affects the classification process and leads to an increase in the number of finer particles turning into the coarse material stream without separation.

\section{Conclusions}

1-Installation of a high efficiency separator tends to increase the grinding capacity and improve the product quality, as the Blaine value of the final product increased from about (310-320) $\mathrm{m}^{2} / \mathrm{kg}$ to (350380) $\mathrm{m}^{2} / \mathrm{kg}$ which corresponds to the target Blaine value required in the market. Presence of a high efficiency separator tends to increase the production rate from 90 ton $/ \mathrm{hr}$ to $110 \mathrm{ton} / \mathrm{hr}$.

2- Installation of a separator system in a closed circuit tends to reduce the specific energy consumption from $60 \mathrm{kWh} /$ ton to about $46 \mathrm{kWh} / \mathrm{ton}$. The calculated Tromp curve results suggested normal performance characteristics of the separator, with the bypass value of $(5.8-9.5 \%)$, and the sharpness of separation was (1.821.93) which was close to the expected 2.0. 
3- Cement quality parameters affecting its performance as a construction material were identified through the Markov chain model; such as the specific surface area, the percent passing through $45-\mu \mathrm{m}$ sieve, and the particle size distribution shape. The developed Markov chain model simulated and analyzed the ideal grade efficiency curve and the response to the changes in the fresh feed rate. The effect on the specific surface area and PSD shape of the final product was consistent with the physical nature of the classification process.

\section{References}

1. Alsahhar A.Cement Tests. Material labs[Internet].

2. ASTM (2014) C204-11.Standard test methods for fineness of hydraulic cement by Air permeability Apparatus. [Internet]. West Conshohocken PA: Serdar Aldanmazlar; Jan 24.

3. Benzer H, Ergun L, Lynch A, Oner M, Gunlu A, Celik I (2001). Modeling cement grinding circuits. Minerals Engineering; 14: 1469-1482.

4. Bhatty J, Miller F, Kosmatka S (2004). Innovations in portland cement manufacturing, CD-ROM: SP400, Portland Cement Association, Skokie, IL,.

5. Cement and Mining Processing AG. CEMAG High Efficiency Cross Flow-classifier (2010).[Brochure].Germany: Cement and Mining Processing (CMP)AG;

6. FLSmidth (2010). FLSmidth ball mill for cement grinding.[Brochure].Denmark: FLSmidth A/S;

7. Holderbank management and consulting .Cement engineering book-separators[Internet] 2000. available from:

8. Holderbank management and consulting. Cement seminar process technology ( Operation of separators) (1993).[Brochure].Switzerland: Holderbank .

9. Kawatra SK. (2006). Advances in comminution.: Colorado. Society for Mining, Metallurgy, and Exploration;2006.

10. Kohlhaas B.(1983) Cement Engineers' Handbook, $4^{\text {th }}$ ed. Otto Labahn,

11. Mejeoumov GG (2007). Improved Cement Quality and Grinding Efficiency by Means of Closed Mill Circuit Modeling.Ph.D. Thesis. Civil Engineering Department, Texas A\&M University.

12. Mizonov V, Berthiaux H, Zhukov V, Bernotat S. Application of multidimensional Markov chains to model kinetics of grinding with internal classification. Int J Miner Process 2004; 74S: S307-S315

13. Mizonov V, Zhukov V, Bernotat S. Simulation of grinding: new approaches. Ivanovo State Power Engineering University Press, Ivanovo, Russia1997

14. T. k. Belhaj; Prof. Dr. M. G. Higazy; Ass. Prof. A. M. Gaafer; and Dr. B. A. K. ELmogy "Productivity Improvement for Cement Industries",Ph.D. Thesis, Faculty of Engineering,Shoubra,Mechanical Engnieering Department, Benha University,2016. 